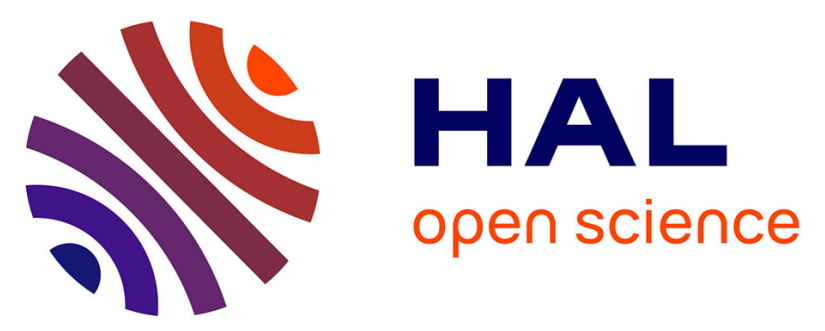

\title{
Possible application of the Environmental Relative Moldiness Index in France: a pilot study in Brittany.
} Delphine Méheust, Pierre Le Cann, Tiina Reponen, Jennie Wakefield, Stephen Vesper, Jean-Pierre Gangneux

\section{- To cite this version:}

Delphine Méheust, Pierre Le Cann, Tiina Reponen, Jennie Wakefield, Stephen Vesper, et al.. Possible application of the Environmental Relative Moldiness Index in France: a pilot study in Brittany.. International Journal of Hygiene and Environmental Health, 2013, 216 (3), pp.333-40. 10.1016/j.ijheh.2012.06.004 . inserm-00817898

\section{HAL Id: inserm-00817898 https://www.hal.inserm.fr/inserm-00817898}

Submitted on 13 May 2014

HAL is a multi-disciplinary open access archive for the deposit and dissemination of scientific research documents, whether they are published or not. The documents may come from teaching and research institutions in France or abroad, or from public or private research centers.
L'archive ouverte pluridisciplinaire HAL, est destinée au dépôt et à la diffusion de documents scientifiques de niveau recherche, publiés ou non, émanant des établissements d'enseignement et de recherche français ou étrangers, des laboratoires publics ou privés. 


\section{Possible Application of the Environmental Relative Moldiness Index in France: a pilot study in Brittany}

Delphine Méheust ${ }^{1,2}$, Pierre Le Cann ${ }^{1,2}$, Tiina Reponen ${ }^{3}$, Jennie Wakefield ${ }^{4}$, Stephen Vesper ${ }^{5}$, Jean-Pierre Gangneux ${ }^{1,6,7, *}$

${ }^{1}$ Institut National de la Santé et de la Recherche Médicale (Inserm), U1085, Institut de Recherche Santé, Environnement \& Travail (IRSET), F-35043 Rennes, France;

${ }^{2}$ Ecole des Hautes Etudes en Santé Publique (EHESP), F-35043 Rennes, France;

${ }^{3}$ University of Cincinnati, Department of Environmental Health, Cincinnati, OH 45267-0056, USA;

${ }^{4}$ Dynamac Corporation, Cincinnati, OH 45268, USA ;

${ }^{5}$ Environmental Protection Agency, Cincinnati, OH 45268, USA ;

${ }^{6}$ Université de Rennes 1, Faculté de Médecine, F-35043 Rennes, France;

${ }^{7}$ Centre Hospitalier Universitaire de Rennes (CHU), Service de Parasitologie-Mycologie, F35033 Rennes, France.

* Corresponding author:

Prof. Jean-Pierre Gangneux

Service de Parasitologie-Mycologie

Faculté de Médecine et Centre Hospitalier Universitaire de Rennes

2 rue du Pr Léon Bernard, CS34317

35043 Rennes Cedex, FRANCE

Tel : 33 (0)2.23.23.44.90 - Fax : 33 (0)2.23.23.46.29

Jean-pierre.gangneux@univ-rennes1.fr 


\begin{abstract}
Our goal was to determine if the US Environmental Relative Moldiness Index (ERMI) scale might have application in France. Twenty homes in Brittany, north western region of France were classified by inspection as "Moldy" or "Non-Moldy". Dust and air samples were collected (MiTest sampler or Coriolis sampler, respectively) from each home and analyzed by quantitative polymerase chain reaction (QPCR) for the 36 fungi that make-up the ERMI. Inspection and ERMI values provided a consistent assessment for $90 \%$ of the homes. Two homes originally classified as "Non-Moldy" were found to fit better into the "Moldy" category based on the QPCR analysis and the ERMI. Dust and air samples analyzed by QPCR provided similar fungal contamination assessments. In conclusion, a metric like the ERMI describes mold burdens in homes on a continuum, as opposed to the frequently used dichotomous approach (moldy vs nonmoldy). Although a larger, random national sampling of French homes is needed, these results suggest that these same 36 fungi may be useful in creating an ERMI for France.
\end{abstract}

\title{
Keywords:
}

Fungi; Molds; Aspergillus; ERMI; QPCR; Home Environment 


\section{Introduction}

The analysis of fungal populations in homes has commonly been based on the collection of short air samples followed by microscopic enumeration, either directly by observing the conidia/spores or by culturing the fungi on one or two media. The World Health Organization Report (WHO, 2009) described these technologies as having serious drawbacks. One of the major recommendations espoused by the Institutes of Medicine report (IOM, 2004) was the need for the development of molecular-based methods of fungal analysis.

United States Environmental Protection Agency (US EPA) researchers developed quantitative PCR (QPCR) assays, based-on unique DNA sequences, for more than 100 fungi (Haugland and Vesper, 2002). Then the US EPA and US Department of Housing and Urban Development (HUD) developed a standardized dust sampling procedure and identified and quantified 36 fungi in dust samples from a random national sampling of US homes. The result was the creation of the Environmental Relative Moldiness Index (ERMI) scale for the US (Vesper et al., 2007).

In the development of the ERMI scale, 26 of the fungi were found commonly associated with water-damaged homes (Group 1). Ten of the fungi were common in all homes (Group 2) because they originate primarily from outdoors (vegetation, soil etc) (Vesper, 2011). The ERMI was calculated as shown in Equation Eq. 1, by taking the sum of the logs of the concentrations of the 26 Group 1 fungi $\left(s_{1}\right)$ and subtracting the sum of the logs of the concentrations of 10 Group 2 fungi $\left(\mathrm{s}_{2}\right)$ (Vesper et al., 2007).

$$
E R M I=\sum_{i=1}^{26} \log _{10}\left(s_{1 i}\right)-\sum_{j=1}^{10} \log _{10}\left(s_{2 j}\right)
$$


The higher the ERMI, the more mold contamination does the home have. In US homes, the ERMI scale ranges from about -10 to 20 (or higher), and about $25 \%$ of homes have ERMI values above 5 (Vesper et al., 2007). Asthma development and exacerbation have been associated with higher ERMI values in the home (Reponen et al., 2011; Kercsmar et al., 2006, respectively).

Most previous studies in French homes have been limited to counting or culturing analyses (Table 1). They allowed, however, the description of major fungal genera and species found in French dwellings. One recent study utilized QPCR to quantify five species of fungi in homes in eastern France and reported significantly higher levels of Cladosporium sphaerospermum DNA in air and surface samples from moisture-damaged homes compared to control homes (Bellanger et al., 2009).

In this study, we wanted to determine the potential application of the ERMI scale to describe fungal contamination in French homes. As a pilot study, we sampled 20 dwellings in the Brittany region of France. We compared the standard dust samples to air samples taken with a cyclonic-based liquid air collector (Bellanger et al., 2012) in these same homes.

\section{Materials and methods}

\section{Home Selection and Classification}

Twenty homes in north western France (Brittany) were selected for QPCR analysis. The selection of homes was based upon ease of availability. An inspection was carried-out between January and March 2011 by the same trained person in all the homes that were then placed in categories of "Moldy" or "Non-Moldy". The "Moldy" homes had visible mold growth or 
"moldy" odor. Among them, the "Moldy" status was a consequence of water damage or ventilation defaults. This classification was not revealed to the analytical laboratory, until after the fungal analysis was completed.

\section{Dust and Air Sampling}

Dust samples were collected from 20 homes by vacuuming $2 \mathrm{~m}^{2}$ in the living room and 2 $\mathrm{m}^{2}$ in a bedroom for $5 \mathrm{~min}$ each with a Mitest ${ }^{\mathrm{TM}}$ sampler-fitted vacuum, directly adjacent to the sofa or bed, respectively. The dust was sieved through a 300 micron pore size mesh to remove large particles and other objects.

The Coriolis cyclone collector (Bertin Technologies, Saint-Quentin-en-Yvelines, France) was used at a flow rate of $300 \mathrm{~L} / \mathrm{min}$ to sample $3 \mathrm{~m}^{3}$ of air in the living room of the 20 homes. The inhabitants were asked to not open the windows the day of the visit. Airborne microorganisms were sampled in collection liquid (AES Chemunex, Bruz, France) with an initial volume of $15 \mathrm{~mL}$. An aliquot of $1.5 \mathrm{~mL}$ of the sample was centrifuged at 5,000 $\mathrm{xg}$ for $15 \mathrm{~min}$ and the the supernatant fluid was removed to keep the pellet in $100 \mu \mathrm{L}$. The dust and air samples were stored at $-20^{\circ} \mathrm{C}$ until the analysis.

\section{Fungal Identification and Quantification using QPCR}

QPCR analysis was performed on $5.0 \pm 0.1 \mathrm{mg}$ of dust. For the air samples, the pellet of $100 \mu \mathrm{L}$ was filtered through a $0.2 \mu \mathrm{m}$ pore size, $45 \mathrm{~mm}$ diameter polycarbonate filter (Millipore Corp) using a Nalgene disposable filtration device (Fisher, product number 09-740-30K). The filter was directly used for the following extraction step. All the samples were spiked with $1 \mathrm{x}$ $10^{6}$ conidia of Geotrichum candidum as an external reference. Each extraction tube was shaken 
in the bead beater (Biospec Products, Bartlesville, OK) for one minute and the DNA purified using the DNA-EZ extraction kit (GeneRite, Cherry Hill, NJ).

Methods and assays have been reported previously for performing quantitative PCR (QPCR) analyses (Haugland et al. 2002; 2004). Briefly, the standard reaction assays contained $12.5 \mu 1$ of "Universal Master Mix" (Applied Biosystems Inc., Foster City, CA), $1 \mu 1$ of a mixture of forward and reverse primers at $25 \mu \mathrm{M}$ each, $2.5 \mu 1$ of a $400 \mathrm{nM}$ TaqMan probe (Applied Biosystems Inc.), $2.5 \mu 1$ of $2 \mathrm{mg} / \mathrm{ml}$ fraction V bovine serum albumin (Sigma Chemical, St. Louis, MO) and $2.5 \mu 1$ of DNA free water (Cepheid, Sunnyvale, CA). To this mix was added 5 $\mu 1$ of the DNA extract from the sample. All primer and probe sequences used in the assays as well as known species comprising the assay groups are at the website:

http://www.epa.gov/nerlcwww/moldtech.htm. Primers and probes were synthesized commercially (Applied Biosystems, Inc.).

Reactions were performed with thermal cycling conditions consisting of 2 minutes at $50^{\circ} \mathrm{C}$, 10 minutes at $95^{\circ} \mathrm{C}$, followed by 40 cycles of 15 seconds at $95^{\circ} \mathrm{C}$ for template denaturation and 1 minute at $60^{\circ} \mathrm{C}$ for probe and primer annealing and primer extension. The Cycle threshold determinations were automatically performed by the instrument ABI 7900 (Applied Biosystems, Inc.) using default parameters. Assays for each target species and the internal reference (Geotrichum candidum) were performed in separate tubes of the 96-well plate format.

\section{Statistical Analyses}

Log10 transformed fungal data and raw ERMI-related measures [Sum of the Logs of Group 1 (SLG 1), Sum of the Logs of Group 2 (SLG 2), and ERMI] were evaluated for the presence of outliers and approximation to the normal distribution using the Scout data analysis program (US EPA, 2008), and for homogeneity of variance using Levene's test in R (R 
Development Core Team, 2011), prior to analyses of mean group differences. Descriptive statistics were computed using the censored Maximum Likelihood Estimation (MLE) and bootstrap resampling with replacement procedures in the $\mathrm{R}$ package fitdistrplus (DelignetteMuller et al., 2010).

The populations of each of the 36 ERMI species in the 10 inspection-classified "Moldy" homes were compared to those of the 10 classified as "Non-Moldy" using the censored MLE ttest equivalent in the R package NADA (Lee, 2010) and verified using that package's equivalent of the nonparametric Peto and Peto modification of the Gehan-Wilcoxon test. Based on an apparent discrepancy between the inspection-classification status and the ERMI scores for two of the French homes originally assigned to the "Non-Moldy" group, these two homes were reclassified as "Uncertain" and the data re-analyzed as above using the censored MLE equivalents of the 3-group ANOVA and 2-group (t-test) contrasts. P-values were adjusted for multiple comparisons following the two-stage Benjamini and Hochberg (1995) step-up procedure in the multtest package (Pollard et al., 2010) running under R, and results for all comparisons were confirmed using the nonparametric Peto and Peto as described above. All estimates and analyses were carried out separately for dust and air samples.

Correlations between $\log 10$ dust and air values were evaluated based on the Pearson Correlation Coefficients computed as part of the parametric Ordinary Least Squares (OLS) censored regression procedure in the Scout software program (US EPA, 2008). Results were checked using the nonparametric Kendall tau procedure in the R package NADA (Lee, 2010).

To evaluate the application of the ERMI scale in French homes, each of the French homes was paired with a single, corresponding US home from the National Survey of 1083 continental US homes (Vesper et al., 2007) using the ERMI value closest to the French ERMI 
value. Nineteen of the 20 matched-pairs ERMI values were within \pm 0.17 units of one another on the ERMI scale. The highest ERMI value among the French homes, 28.79, was paired with the closest US ERMI value of 27.02, a difference of 1.77 units. Differences between group $\log 10$ means were analyzed using the parametric censored MLE version of the paired t-test in the R package survival (Therneau and Lumley, 2011), and confirmed using the nonparametric equivalent implemented in that package. Both parametric analyses and nonparametric checks were carried out initially using all 20 French-US home pairs, and the results confirmed by parallel analyses omitting the pair with the outlying ERMI difference.

\section{Results}

The bootstrap estimates of average $\log 10$ concentration for each of the 36 fungi in French $(\mathrm{N}=20)$ and US $(\mathrm{N}=1083)$ homes and results of statistical analyses are presented in Table 2 . Very few ERMI species concentrations were found to be greater in US homes than in French homes (e.g. Aspergillus penicillioides, Epicoccum nigrum), and none of these US > French home differences reached statistical significance. In contrast, 22 species were found in significantly greater concentrations in these French homes (e.g Aspergillus restrictus, Wallemia sebi, etc.) relative to those in the US.

Since the number of French homes was very small compared to the number of homes in the US data set, each of the French homes was matched to a US home with the same or closest ERMI value (generally $<0.17$ ERMI units), and the species-specific and ERMI-related metrics were compared. There were 15 Group 1 fungi that were statistically different in the ERMI-paired US and French homes and 5 Group 2 fungi (Table 3). About half of these Group 1 fungi (9/15) were more abundant in French homes than US but all five of the Group 2 fungi were more 
common in these French homes. The Sum of the Logs of the Group 1 species was comparable in US and French homes. However, the Sum of the Logs of the Group 2 fungi was significantly greater in French homes.

The ERMI values for each of the French homes are shown in Figure 1 along with their visual/olfactory-based classification as to "Moldy" and "Non-Moldy". The ERMI values of homes 8 and 14 appear to be nearer the "Moldy" homes' ERMI values. (These two homes were resampled and the repeat ERMI values were comparable to the original ERMI values.) Therefore, the visual/olfactory classification of the homes was compared to the ERMI classification based on Maximum Likelihood Estimation (MLE) group differences analysis (Table 4). There were three categories "Moldy" $(\mathrm{n}=10)$, "Non-Moldy" $(\mathrm{n}=8)$ and "Uncertain" $(n=2)$. This comparison was completed for both the dust and air samples.

The MLE group differences analysis demonstrated that the ERMI values for the ten "Moldy" homes were significantly different from the eight "Non-Moldy" homes but that the two "Uncertain" homes were not different from the ten "Moldy" homes. However, the ERMI values for the two "Uncertain" homes were significantly different from the eight "Non-Moldy" homes. Therefore the two "Uncertain" are reclassified as "Moldy". As a result of this reclassification, the homes were re-inspected, and dust was again sampled. The ERMI values obtained for the first and second visits were similar (data not shown). It is possible that the molds in home 8 could be related to water damage in the bathroom that occurred 14 months before and the molds in home 14 could be related to the wooden floor frequently washed. These differences in the ERMI values were driven by the differences in the Sum of the Group 1 fungi, since the Sum of the Group 2 fungi were not significantly different (Table 4). 
Although a true ERMI analysis (based on $5 \mathrm{mg}$ of dust) cannot be completed on air samples, an ERMI-like analysis was completed on the air samples (Table 4). This analysis also demonstrated that the ten ERMI-like values in "Moldy" homes' were significantly different from the ones obtained for eight "Non-Moldy" homes. Therefore the relationship between the concentrations of the fungi in the dust and air samples was investigated.

Pearson correlation analysis showed that the populations of five Group 1 fungi and two Group 2 fungi were significantly correlated in the twenty dust and air samples (Table 5). The Sum of the Logs of the Group 1 fungi were also correlated but not the Sum of the Logs of the Group 2 fungi. The ERMI or ERMI-like values were also correlated in the dust and air samples. In many cases the ERMI-like values, based on the air samples, also agreed with the inspection classification. However, there were some notable exceptions, including homes 2, 3 and 7 (Figure 2, $\mathrm{A}$ and $\mathrm{B})$.

\section{Discussion}

Mold inspectors tend to classify homes as either "Moldy" or "Non-Moldy." This is an over simplification. The contamination of homes would be better expressed on a continuum from low to high based on the populations of fungi. The ERMI scale provides this type of continuum; built with a random national selection of US homes. The ERMI values from the 20 French homes can be looked at as a continuum relative to each other.

When the ERMI values in these homes were assembled from lowest to highest, then compared to the inspection classification, the homes on either the left side or right of the scale were in agreement with inspection (Figure 1B). Two homes ( 8 and 14) classified by inspection 
as "Non-Moldy" had ERMI values in between two homes inspector-classified as "Moldy". By examining the populations of fungi in these two homes, we determined that these homes fit better into the "Moldy" category. Therefore, the water damage and fungal growth may have been hidden in these two homes. This often happens when a water problem is corrected but the damaged materials are not removed. These materials provide a continuing reservoir of fungal contamination in the home even after the moisture is gone.

It might be more accurate to think of the homes 8 and 14 and by extension, 17, 18 and 20, as a "Middle-Moldiness" category. If there is a demarcation between Moldy and Non-Moldy, it may depend on the question being considered. For example, ERMI values in US infant homes above five where predictive of the development of asthma (Reponen et al., 2011). Use of the ERMI provides a more quantitative approach to describing contamination than traditional methods like counting and culturing (Vesper, 2010), since it utilizes a standard sampling procedure and DNA-based analysis which provides accurate identification and quantification of the fungi (Haugland et al., 2004).

About half of the fungi were in similar concentrations in US and in our sample of French homes but the others were split; sometimes a particular fungus was more common in France (especially some of the Group 2 fungi) and others in the US. Even so, the $90 \%$ agreement between ERMI values and inspection-classification of these French homes suggested that most of the 36 fungi may be adequate in creating an ERMI scale for France. However, since only 20 homes in Brittany were studied, we recognize this assessment of the 36 fungi remains to be established in different regions of the country.

Five of the Group 1 and two of the Group 2 fungi were highly correlated in the dust and air samples. Even though the ERMI is by definition based on a dust sample, we calculated for 
the first time an "ERMI-like" value for the air samples. The result was a significant correlation between the ERMI and ERMI-like results. Some of the differences between ERMI and ERMIlike estimations of contamination may be that the air samples were collected in the living room but dust samples were collected in both the living room and bedroom. When the ERMI-like values in these homes were assembled from lowest to highest, then compared to the inspection classification, the homes were globally in agreement with inspection (Figure 2B). Some fungal species were found to be correlated in dust and air samples (Table 5). Although air sampling is a common technique to characterize the respiratory exposure of the inhabitants, spatio-temporal variations are one of the limitations of this approach. In contrast, accumulated dust in the home can be used to assess long-term bioaerosol exposure. Cautiously, we suggest that the ERMI-like values in air samples provide additional support to the use of these 36 fungi to describe fungal contamination in French homes based on the ERMI.

The ERMI scale has been applied to other countries besides the US including, the UK (Vesper et al., 2005) and Singapore (Yap et al., 2009). In these countries, the 26 Group 1 fungi had a common occurrence not unlike the US. However, the Group 2 species were more variable than in US homes. For example, in the tropical climate of Singapore many of the Cladosporium species were found in lower concentrations than typically found in the US. (However, in Singapore, the samples came from shopping centers and not homes).

In France, based on this limited sample of homes, some of the Group 2 fungi might be more abundant compared to the US. This might be due to windows being more commonly open for ventilation in French homes compared to the US which rely more on air-conditioning (Vandentorren et al., 2006). About half of the residential building stock in France was built before 1967, i.e. before the first regulations in 1969 requiring whole-house ventilation. 
Approximately, $70 \%$ of the dwellings have mechanical ventilation (35\%) or natural ventilation (34.5\%) installed but 21.5\% have no ventilation system (Dimitroulopoulou 2011). Therefore we cannot expect that the ERMI scale in France will be the same as in the US.

There have been previous attempts to create a metric for defining fungal contamination in French homes using air samples and culture-based quantification (Table 1). There are several problems with this approach: only viable fungi will grow, the media utilized will select for certain fungi, samples can only be taken for a limited time or the culture plates become overcrowed, and significant experience is required to identify the many different fungi. Realizing these limitations, a strategy based on QPCR testing five fungi was evaluated in eastern part of France (Bellanger et al., 2009). In this study, the sampling procedure utilized were relatively short air samples, i.e. 100 liters over $33 \mathrm{~min}$, and surface swab samples. In spite of the low levels of fungal detection, Cladosporium sphaerospermum and Aspergillus versicolor, two of the ERMI Group 1 fungi, were shown to be in higher concentrations in moisture-damaged homes compared to control homes. Therefore including 36 fungi in the analysis of dust samples should produce an even more robust assessment. Besides, these 36 fungal indicators seem representative of the biodiversity found in many French studies (Table 1).

The Mold Specific QPCR technology is fairly expensive, especially when compared to some of the traditional approaches to mould analysis (Vesper, 2011). However, the price of this analysis will decrease with the development of automated solution (Nucleic acid extraction and PCR analysis). Besides, the ERMI analysis is a fast standardized method that provides an understandable exposure scale for inhabitants. However, many needs remain in creating a French ERMI. 
The most urgent need is to sample a larger number of homes as only 20 homes were tested in the current study. The ERMI scale in the US tested approximately 1100 homes for a population of 310 million people. In France with a population of 65 million, one might estimate that about $20 \%$ as many or 220 homes would need to be sampled. The additional problem with our study was that it represented homes in one small geographic area. What is needed is a random national sampling of homes to create a French ERMI. Then, a French ERMI would be of special interest to study the impact of molds on respiratory health during chronic pulmonary diseases and to monitor the efficacy of preventive strategies.

In conclusion, the creation of the ERMI scale for US homes was based on a random national sampling of homes which was designed to represent the entire spectrum of US housing conditions. A similar random sampling and analysis of French housing is needed to create a similar scale for France. However, our results suggest that most of the fungi from the US ERMI panel might be sufficient as a starting place to create the index and that an ERMI-like index could also be applied on air samples. 


\section{Acknowledgements}

Delphine Méheust's fellowship as well as home visits were funded by French School of Public Health.

\section{Notice}

The U.S. Environmental Protection Agency (EPA) through its Office of Research and Development, partially funded and collaborated in the research described here. It has been subjected to the Agency's peer review and has been approved as an EPA publication. Mention of trade names or commercial products does not constitute endorsement or recommendation by the EPA for use. Commercial use of the ERMI technology can provide royalties to the EPA. 


\section{References}

Bellanger, A.P., Reboux, G., Roussel, S., Grenouillet, F., Didier-Scherer, E., Dalphin, J.C., and Millon, L., 2009. Indoor fungal contamination of moisture-damaged and allergic patient housing analyzed using real-time PCR. Lett. Appl. Microbiol. 49, 260-266.

Bellanger, A. P. , Reboux, G. , Scherer, E. , Vacheyrou, M. and Millon, L., 2012. Contribution of a Cyclonic-Based Liquid Air Collector for Detecting Aspergillus fumigatus by QPCR in Air Samples. J. Occup. Environ. Hyg. 9, D7 - D11.

Benjamini, Y., and Hochberg, Y., 1995. Controlling the false discovery rate: A practical and powerful approach to multiple testing. J. R. Statist. Soc. B 57, 289-300.

Boutin-Forzano, S., Charpin-Kadouch, C., Chabbi, S., Bennedjai, N., Dumon, H. and Charpin, D., 2004 Wall relative humidity: a simple and reliable index for predicting Stachybotrys chartarum infestation in dwellings. Indoor Air 14, 196-199.

Dassonville, C., Demattei, C., Detaint, B., Barral, S., Bex-Capelle, V., and Momas, I., 2008. Assessment and predictors determination of indoor airborne fungal concentrations in Paris newborn babies' homes. Environ. Res. 108, 80-85.

Delignette-Muller, M.L., Pouillot, R., Denis, J.-B., and Dutang, C., 2010. Fitdistrplus: help to fit of a parametric distribution to non-censored or censored data. $\mathrm{R}$ package version $0.1-2$.

Dimitroulopoulou, C., 2012. Ventilation in European dwellings: A review. Building and Environment 47, 109-125.

Haugland, R., and Vesper, S., 2002. Identification and quantification of specific fungi and 
bacteria. Patent 6,387,652 Granted May 14, 2002.

Haugland, R.A., Brinkman, N.E., and Vesper, S.J., 2002. Evaluation of rapid DNA extraction methods for the quantitative detection of fungal cells using real time PCR analysis. J.

Microbiol. Meth. 50, 319-323

Haugland, R.A., Varma, M., Wymer, L.J., and Vesper, S.J., 2004. Quantitative PCR of selected Aspergillus, Penicillium and Paecilomyces species. Syst. Appl. Microbiol. 27, 198-210.

Institute of Medicine (IOM), National Academies of Science. Damp Indoor Spaces and Health. Washington DC: The National Academies Press; 2004, 355 p.

Kercsmar, C.M., Dearborn, D.G., Schluchter, M.D., Xue, L., Kirchner, H.L., Sobolewski, J., Greenberg, S.J., Vesper, S.J., Allan, T., 2006. Reduction in asthma morbidity in children as a result of home remediation aimed at moisture sources. Environ. Health. Perspect.

$114,1574-1580$.

Lee, L. NADA: Nondetects and data analysis for environmental data. R package version 1.5-3. 2010.

Pollard, K.S., Houston, K., Gilbert, H.N., Ge, Y., Taylor, S., and Dudoit, S. Multtest: Resampling-based multiple hypothesis testing. R package version 2.8.0. 2010.

R Development Core Team. R: A Language and Environment for Statistical Computing. R version 2.13.2. 2011.

Reboux, G., Bellanger, A.P., Roussel, S., Grenouillet, F., Sornin, S., Piarroux, R., Dalphin, J.C., 
Millon, L., 2009. Indoor mold concentration in Eastern France. Indoor Air 19, 446-453.

Reponen, T., Vesper, S., Levin, L., Johansson, E., Burkle, J., Ryan, P., Grinspun, S.A., Zheng,

S., Bernstein, D.I., Lockey, J., Villareal, M., Khurana Hershey, G.K., LeMasters, G., 2011.

High Environmental Relative Moldiness Index during infancy as predictor

of age seven asthma. Ann. Allergy Asthma Immunol. 107, 120-126.

Roussel, S., Reboux, G., Bellanger, A.P., Sornin, S., Grenouillet, F., Dalphin, J.C., Piarroux, R., and Millon, L., 2008. Characteristics of dwellings contaminated by moulds. J. Environ. Monit. 10, 724-729.

Therneau, T., and Lumley, T., 2011. Survival analysis, including penalized likelihood. R package version 2.36-9.

U.S. Environmental Protection Agency ( US EPA). Scout Version 1.00.01, A Statistical Software Package for the Classical and Robust Analysis of Univariate and Multivariate Data Sets with and without Non-detect Observations. 2008. The Software Scout 1.00.01 can be freely downloaded from the E.S. EPA web site at:

http://www.epa.gov/nerlesd1/databases/scout/abstract.htm

Vandentorren, S., Bretin, P., Zeghnoun, A., Mandereau-Bruno, L., Croisier, A., Cochet, C., Ribéron, J., Siberan, I. , Declercq, B., Ledrans, M., 2006. August 2003 heat wave in France: risk factors for death of elderly people living at home. Eur J Public Health 16, 583-591.

Vesper, S., 2011. Traditional mould analysis compared to a DNA-based method of mould analysis. Crit. Rev. Microbiol. 37, 15-24. 
Vesper, S.J., McKinstry, C., Haugland, R.A. Wymer, L., Ashley, P., Cox, D., DeWalt, G., and Friedman, W., 2007. Development of an environmental relative moldiness index for homes in the U.S. J. Occup. Environ. Med. 49, 829-833.

Vesper, S.J., Wymer, L.J., Meklin, T., Varma, M., Stott, R., Richardson, M., Haugland, R.A., 2005. Comparison of populations of mould species in homes in the UK and USA using Mold-Specific Quantitative PCR (MSQPCR). Lett. Appl. Microbiol. 41, 367-373.

World Health Organization (WHO) Europe., 2009. WHO guidelines for indoor air quality: Dampness and mould. Copenhagen, Denmark: WHO.

Yap, J., Toh, Z.A., Goh, V., Ng, L.C., Vesper, S., 2009. Assessment of mould concentrations in Singapore shopping centers using Mould Specific Quantitative PCR (MSQPCR) analysis. Indian J. Microbiol. 49, 290-293. 
Table 1. The main fungal species found in dwellings from different parts of France.

\begin{tabular}{|c|c|c|c|}
\hline Reference & Part of France & Fungal analysis & Fungal species \\
\hline Bellanger et al., 2009 & $\begin{array}{l}\text { Franche-Comté, } \\
\text { East of France }\end{array}$ & $\begin{array}{l}\text { Culture and QPCR analysis } \\
\text { (air samples and surface } \\
\text { samples by swabbing) }\end{array}$ & $\begin{array}{l}\text { Alternaria alternata } \\
\text { Aspergillus versicolor } \\
\text { Cladosporium sphaerospermum } \\
\text { Penicillium chrysogenum } \\
\text { Stachybotrys chartarum }\end{array}$ \\
\hline Boutin-Forzano et al., 2004 & $\begin{array}{l}\text { Marseille area, } \\
\text { South East of France }\end{array}$ & $\begin{array}{l}\text { Microscopic identification } \\
\text { (surface samples by the } \\
\text { gummed paper technique) }\end{array}$ & $\begin{array}{l}\text { Many species including*: } \\
\text { Acremonium sp. } \\
\text { Alternaria sp. } \\
\text { Aspergillus glaucus } \\
\text { Aspergillus versicolor } \\
\text { Chaetomium sp. } \\
\text { Cladosporium sphaerospermum } \\
\text { Penicillium sp. } \\
\text { Stachybotrys chartarum } \\
\text { Ulocladium sp. }\end{array}$ \\
\hline Dassonville et al., 2008 & $\begin{array}{l}\text { Paris city, } \\
\text { North of France }\end{array}$ & $\begin{array}{l}\text { Culture analysis } \\
\text { (air samples) }\end{array}$ & $\begin{array}{l}\text { Alternaria sp. } \\
\text { Aspergillus fumigatus } \\
\text { Aspergillus niger } \\
\text { Aspergillus versicolor } \\
\text { Aspergillus sp. } \\
\text { Chaetomium sp. } \\
\text { Cladosporium herbarum } \\
\text { Cladosporium sp. } \\
\text { Fusarium sp. } \\
\text { Geotrichum sp. } \\
\text { Penicillium chrysogenum } \\
\text { Penicillium sp. } \\
\text { Stachybotrys } s p . \\
\text { Ulocladium } s p .\end{array}$ \\
\hline Reboux et al., 2009 & $\begin{array}{l}\text { Franche-Comté, } \\
\text { East of France }\end{array}$ & $\begin{array}{l}\text { Culture analysis } \\
\text { (air samples and surface } \\
\text { samples by swabbing) }\end{array}$ & $\begin{array}{l}\text { Many species including*: } \\
\text { Alternaria sp. } \\
\text { Aspergillus fumigatus } \\
\text { Aspergillus niger } \\
\text { Aspergillus versicolor } \\
\text { Aspergillus sp. } \\
\text { Cladosporium sp. } \\
\text { Eurotium amstelodami } \\
\text { Penicillium sp. } \\
\text { Rhodotorula sp. } \\
\text { Ulocladium chartarum } \\
\text { Wallemia sebi }\end{array}$ \\
\hline
\end{tabular}

* Fungal species with a frequency of detection equal or higher than $9 \%$ in environmental samples

Fungal species highlighted in grey are not quantified in the ERMI metric 
Table 2. Comparison of the average $\log 10$ concentration of ERMI species in French homes $(\mathrm{n}=20)$ and United States homes $(\mathrm{n}=1083)$ dust samples. Significant differences are flagged in bold type.

\begin{tabular}{|l|} 
\\
\hline \\
\hline Fungus \\
\hline Group 1 \\
\hline Aspergillus flavus \\
\hline Aspergillus fumigatus \\
\hline Aspergillus niger \\
\hline Aspergillus ochraceus \\
\hline Aspergillus penicillioides \\
\hline Aspergillus restrictus \\
\hline Aspergillus sclerotiorum \\
\hline Aspergillus sydowii \\
\hline Aspergillus unguis \\
\hline Aspergillus versicolor \\
\hline Aureobasidium pullulans \\
\hline Chaetomium globosum \\
\hline Cladosporium sphaerospermum \\
\hline Eurotium group \\
\hline Paecilomyces variotii \\
\hline Penicillium brevicompactum \\
\hline Penicillium corylophilum \\
\hline Penicillium crustosum (group 2) \\
\hline Penicillium purpurogenum \\
\hline Penicillium spinulosum \\
\hline Penicillium variabile \\
\hline
\end{tabular}

Average $\log 10$ Concentration cells / mg dust

\section{united states}

$\begin{array}{rrrr}-0.0029 & -0.4737 & 0.02 & 0.9 \\ \mathbf{0 . 9 5 2 0} & 0.2442 & 13.03 & \mathbf{0 . 0 0 0 3} \\ \mathbf{0 . 8 4 9 7} & 0.3689 & 5.88 & \mathbf{0 . 0 1 5} \\ \mathbf{. 0 2 1 7 5} & -1.0679 & 4.36 & \mathbf{0 . 0 3 7} \\ 1.4116 & 1.8766 & 2.31 & 0.13 \\ \mathbf{3 . 3 4 4 8} & -3.8588 & 89.75 & <\mathbf{0 . 0 0 0 1} \\ -0.9484 & -0.7155 & 0.44 & 0.51 \\ -0.9836 & -1.0947 & 1.24 & 0.26 \\ -0.5942 & -1.3549 & 0.22 & 0.64 \\ \mathbf{1 . 2 9 3 2} & -0.9182 & 27.29 & <\mathbf{0 . 0 0 0 1} \\ \mathbf{3 . 6 3 1 8} & 2.4103 & 28.89 & <\mathbf{0 . 0 0 0 1} \\ 0.3631 & -0.0404 & 3.43 & 0.064 \\ \mathbf{1 . 6 9 9 5} & 1.0266 & 7.95 & \mathbf{0 . 0 0 4 8} \\ 1.8888 & 2.1777 & 1.74 & 0.19 \\ -0.2112 & -0.1482 & 2.95 & 0.086 \\ 2.8924 & 0.1293 & 57.47 & <\mathbf{0 . 0 0 0 1} \\ \mathbf{0 . 7 6 3 9} & -2.1491 & 23.55 & <\mathbf{0 . 0 0 0 1} \\ \mathbf{2 . 2 5 1 6} & -4.4096 & 93.46 & <\mathbf{0 . 0 0 0 1} \\ \mathbf{- 0 . 0 3 0 5} & -0.9261 & 17.05 & <\mathbf{0 . 0 0 0 1} \\ \mathbf{0 . 3 9 2 0} & -1.0114 & 22.52 & \mathbf{0 . 0 0 0 1} \\ -0.1404 & 0.0771 & 1.05 & 0.31\end{array}$




\begin{tabular}{|l|}
\hline Scopulariopsis brevicaulis \\
\hline Scopulariopsis chartarum \\
\hline Stachybotrys chartarum \\
\hline Trichoderma viride \\
\hline Wallemia sebi \\
\hline Group 2 \\
\hline Acremonium strictum \\
\hline Alternaria alternata \\
\hline Aspergillus ustus \\
\hline Cladosporium cladosporioides type 1 \\
\hline Cladosporium cladosporioides type 2 \\
\hline Cladosporium herbarum \\
\hline Epicoccum nigrum \\
\hline Mucor amphibiorum \\
\hline Penicillium chrysogenum type 2 \\
\hline Rhizopus stolonifer \\
\hline
\end{tabular}

$\begin{array}{rrrr}0.3280 & 0.0319 & 1.42 & 0.23 \\ \mathbf{1 . 0 6 3 1} & -0.2679 & 51.46 & <\mathbf{0 . 0 0 0 1} \\ \mathbf{0 . 5 8 3 7} & -0.6000 & 9.15 & \mathbf{0 . 0 0 2 5} \\ \mathbf{1 . 3 2 2 8} & -0.2731 & 79.08 & <\mathbf{0 . 0 0 0 1} \\ \mathbf{3 . 5 6 7 2} & 1.0716 & 72.04 & <\mathbf{0 . 0 0 0 1} \\ & & & \\ 0.3618 & 0.3081 & 0.01 & 0.92 \\ 1.5724 & 1.5074 & 0.1 & 0.75 \\ -0.8930 & -0.2626 & 0.15 & 0.7 \\ \mathbf{3 . 5 4 2 4} & 2.5289 & 31.61 & <\mathbf{0 . 0 0 0 1} \\ \mathbf{1 . 7 7 5 6} & 0.4489 & 41.29 & <\mathbf{0 . 0 0 0 1} \\ \mathbf{3 . 2 5 4 9} & 1.3839 & 42.1 & <\mathbf{0 . 0 0 0 1} \\ 1.8978 & 2.0482 & 0.29 & 0.59 \\ \mathbf{1 . 7 2 9 3} & 1.1645 & 8.28 & \mathbf{0 . 0 0 4} \\ \mathbf{2 . 2 6 3 9} & 0.4799 & 46.79 & <\mathbf{0 . 0 0 0 1} \\ \mathbf{0 . 4 7 7 1} & -0.4986 & 25.65 & <\mathbf{0 . 0 0 0 1}\end{array}$


Table 3. Comparison of the average concentrations of ERMI species $(\log 10)$ and ERMI-related metrics in US and French homes when matched by comparable ERMI values. The higher concentration is bolded for each species under the French or United States column.

\begin{tabular}{|c|c|c|c|c|}
\hline Fungus & $\begin{array}{l}\text { Average } \log 10 \\
\text { Concentration } \\
\text { cells / mg dust } \\
\text { France }\end{array}$ & $\begin{array}{l}\text { Average } \log 10 \\
\text { Concentration } \\
\text { cells / mg dust } \\
\text { United States }\end{array}$ & $\mathrm{Chi}^{2}$ & p-value \\
\hline Group 1 & & & & \\
\hline Aspergillus penicillioides & 1.4116 & 3.3462 & 28.44 & $<0.0001$ \\
\hline Aspergillus restrictus & 3.3448 & -2.4873 & 31.69 & $<0.0001$ \\
\hline Aspergillus sydowii & -0.9836 & 0.7869 & 10.6 & 0.0011 \\
\hline Aspergillus unguis & -0.5942 & 0.4171 & 11.02 & $<0.0001$ \\
\hline Aureobasidium pullulans & 3.6318 & 2.3335 & 25.65 & $<0.0001$ \\
\hline Eurotium group & 1.8888 & 2.8114 & 6.74 & 0.0094 \\
\hline Paecilomyces variotii & -0.2112 & 0.6630 & 15.16 & $<0.0001$ \\
\hline Penicillium brevicompactum & 2.8924 & 0.9360 & 19.35 & $<0.0001$ \\
\hline Penicillium corylophilum & 0.7639 & -0.8178 & 6.48 & 0.011 \\
\hline Penicillium crustosum (group 2) & 2.2516 & -1.3009 & 65.77 & $<0.0001$ \\
\hline Penicillium spinulosum & 0.3920 & -0.2246 & 5.99 & 0.014 \\
\hline Penicillium variabile & -0.1404 & 0.5920 & 3.9 & 0.048 \\
\hline Scopulariopsis chartarum & 1.0631 & 0.1327 & 11 & 0.0009 \\
\hline Trichoderma viride & 1.3228 & 0.0156 & 26.95 & $<0.0001$ \\
\hline Wallemia sebi & 3.5672 & 2.1589 & 13.16 & 0.0003 \\
\hline Group 2 & & & & \\
\hline $\begin{array}{l}\text { Cladosporium cladosporioides } \\
\text { type } 1\end{array}$ & 3.5424 & 2.6874 & 14.54 & 0.0001 \\
\hline $\begin{array}{l}\text { Cladosporium cladosporioides } \\
\text { type } 2\end{array}$ & 1.7756 & 0.8260 & 21.56 & $<0.0001$ \\
\hline Cladosporium herbarum & 3.2549 & 1.6393 & 22.94 & $<0.0001$ \\
\hline Penicillium chrysogenum type 2 & 2.2639 & 1.3407 & 7.93 & 0.0049 \\
\hline
\end{tabular}




\begin{tabular}{|l|rrrr|}
\hline Rhizopus stolonifer & $\mathbf{0 . 4 7 7 1}$ & -0.1674 & 6.96 & 0.0083 \\
& & & & \\
& & & & \\
Sum of the Logs (Group I) & 31.0095 & 26.1484 & 3.17 & 0.075 \\
\hline Sum of the Logs (Group II) & $\mathbf{1 7 . 5 4 4 5}$ & 12.6818 & 10.61 & 0.0011 \\
\hline ERMI (Group I - Group II) & 13.4995 & 13.4929 & 0 & 0.97
\end{tabular}


Table 4. Comparison of average ERMI-related values computed from air and dust samples in French homes. Based on an apparent discrepancy between the inspection-classification status and the ERMI scores for two of the French homes originally assigned to the "Non-Moldy" group, these two homes were re-classified as "Uncertain" and the data re-analyzed using the censored Maximum Likelihood Estimation equivalents of the 3-categories ANOVA and 2categories (t-test) contrasts. P-values were adjusted for multiple comparisons following the twostage Benjamini and Hochberg (1995) step-up procedure and results for all comparisons were confirmed using the nonparametric Peto and Peto, as described in materials and methods.

Contrast p-values with statistically significant differences are shown in bold.

\section{Dust Samples}

\section{Three-categories ANOVA}

10 "Mold" vs 8 "non-Moldy" vs. 2

"Uncertain"

\section{T-test}

10 "Mold" vs 8 "non-Moldy"

10 "Mold" vs 2 "Uncertain"

8 "non-Moldy" vs 2 "Uncertain"

Air Samples

\begin{tabular}{cccccc} 
Sum Group 1 & Sum Group 2 & \multicolumn{2}{c}{ ERMI } \\
$\mathrm{Chi}^{2}$ & $\mathbf{P}$ & $\mathrm{Chi}^{2}$ & $\mathrm{P}$ & $\mathrm{Chi}^{2}$ & $\mathrm{P}$
\end{tabular}

$\begin{array}{llllll}18.32 & <0.001 & 3.8 & 0.15 & 22.48 & <0.001\end{array}$

$\begin{array}{rrrrrr}16.41 & <0.001 & 2.85 & 0.24 & \mathbf{2 0 . 2 3} & <0.001 \\ 2.35 & 0.31 & 1.33 & 0.51 & 2.27 & 0.32 \\ \mathbf{6 . 1 3} & \mathbf{0 . 0 4 7} & 0.09 & 0.96 & \mathbf{7 . 6 9} & \mathbf{0 . 0 2 1}\end{array}$

Sum Group 1 Sum Group 2 ERMI-Like

$\begin{array}{lllllll}\mathrm{Chi}^{2} & \mathrm{p} & \mathrm{Chi}^{2} & \mathrm{P} & \mathrm{Chi}^{2} & \mathrm{P}\end{array}$

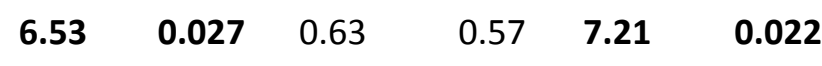

Three-categories ANOVA

10 "Mold" vs 8 "non-Moldy" vs. 2 
"Uncertain"

T-test

10 "Mold" vs 8 "non-Moldy"

10 "Mold" vs 2 "Uncertain"

$\begin{array}{llllll}6.8 & 0.099 & 0.87 & 0.65 & 7.37 & \mathbf{0 . 0 2 5}\end{array}$

8 "non-Moldy" vs 2 "Uncertain"

$\begin{array}{llllll}0.59 & 0.74 & 0.01 & 1 & 0.98 & 0.61\end{array}$

$\begin{array}{llllll}1.92 & 0.38 & 1.55 & 0.46 & 0.76 & 0.68\end{array}$


Table 5. Pearson correlation between dust and air samples from twenty French homes.

$\begin{array}{lccc}\text { Fungus } & \begin{array}{c}\text { Pearson } \\ \text { correlation }\end{array} & \text { F } & \text { p } \\ \text { Aspergillus restrictus } & 0.616 & 10.99 & 0.004 \\ \text { Chaetomium globosum } & 0.611 & 10.7 & 0.004 \\ \text { Eurotium group } & 0.757 & 24.19 & <0.001 \\ \text { Penicillium corylophilum } & 0.448 & 4.508 & 0.048 \\ \text { Penicillium purpurogenum } & 0.67 & 14.64 & 0.001 \\ \text { Acremonium strictum } & 0.599 & 10.06 & 0.005 \\ \text { Rhizopus stolonifer } & 0.506 & 6.206 & 0.023 \\ \text { Sum of Group 1 } & 0.553 & 7.933 & 0.011 \\ \text { Sum of Group 2 } & 0.363 & 2.731 & 0.116 \\ \text { ERMI vs ERMI-like } & 0.507 & 6.241 & 0.022\end{array}$


Figure 1. A) ERMI values for the 20 French homes and their visually/olfactory classification into "Moldy" and "Non-Moldy" categories. B) ERMI values assembled from lowest to highest. Black bars are homes classified by inspection as "Moldy" and the gray bars were homes classified as "Non-Moldy".

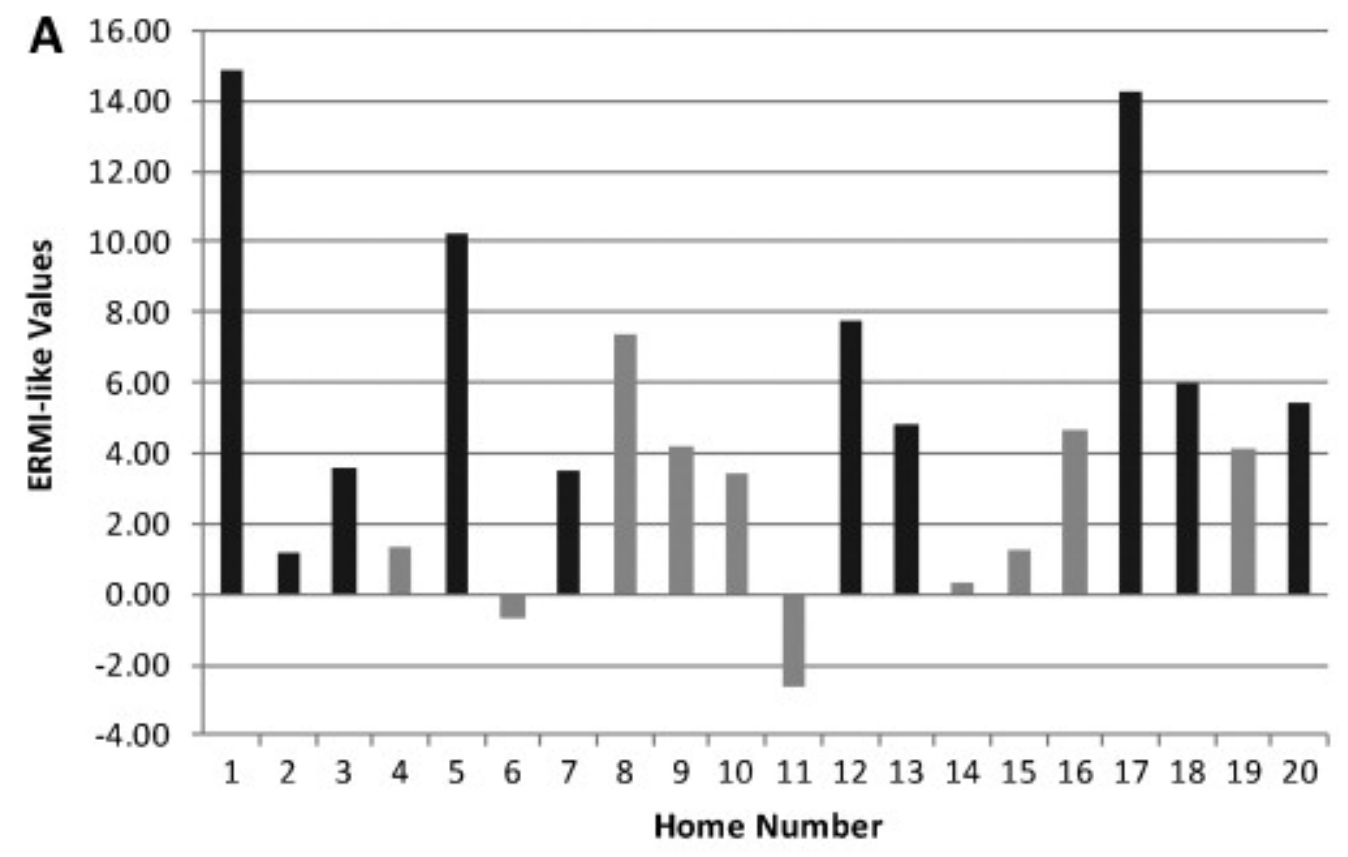

Figure 2. A) ERMI-like values (based on air samples) for the 20 French homes and their visually/olfactory classification into "Moldy" and "Non-Moldy" categories. B) ERMI-like values (based on air samples) assembled from lowest to highest. Black bars are homes classified by inspection as "Moldy" and the gray bars were homes classified as "Non-Moldy". 


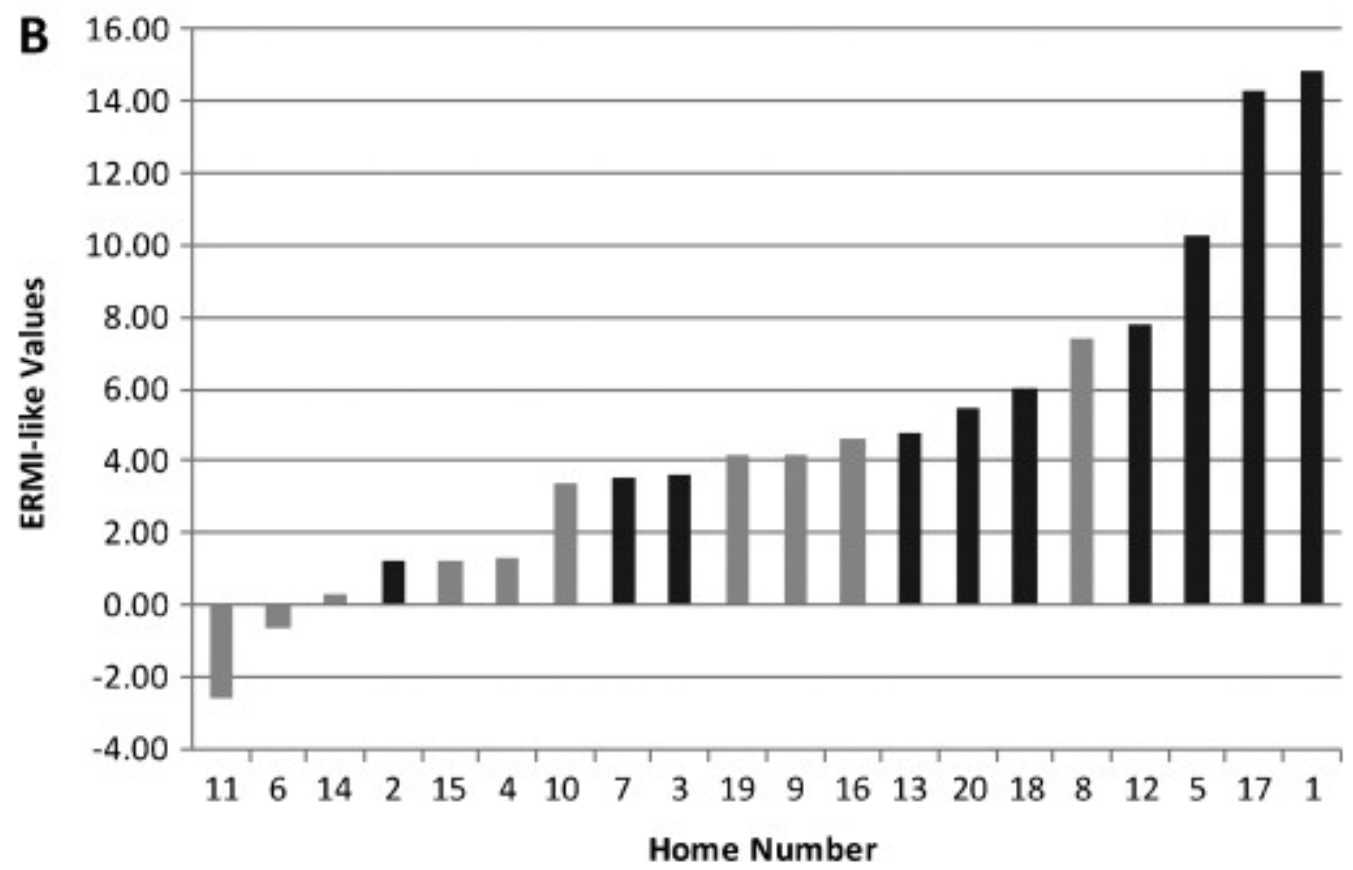

